\title{
Trends of Fog and Visibility in Taiwan: Climate Change or Air Quality Improvement?
}

\author{
Maylin Maurer $^{1 *}$, Otto Klemm ${ }^{1 * *}$, Hanna L. Lokys ${ }^{1}$, Neng-Huei Lin ${ }^{2}$ \\ ${ }^{1}$ Climatology Working Group, University of Münster, 48149 Münster, Germany \\ ${ }^{2}$ Department of Atmospheric Sciences, National Central University, Taoyuan 32001, Taiwan
}

\begin{abstract}
This study provides insight into how the visibility in Taiwan has varied over time and what the main drivers of these visibility changes are. From 1985 to 2016, urban inland sites showed increases in visibility and decreases in the frequency of hazy and/or foggy days, whereas urbanized and rural coastal regions either showed no clear trend or even an overall decrease in visibility. Over the most recent 5 to 10 years, a consistent increase in the visibility and decrease in the haze frequency has been found for most of the stations, except for the rural to suburban regions.

In general, visibility is driven by the relative humidity $(\mathrm{rH})$ and the mass concentration of aerosol particles $(\mathrm{PM})$. On the one hand, the combination of climate change and urbanization, resulting in a rise in temperature (on average, $+0.035^{\circ} \mathrm{C} \mathrm{y}^{-1}$ ) and an associated overall decrease in $\mathrm{rH}$ (on average, $-0.125 \% \mathrm{y}^{-1}$ ), has had a positive influence on long-term visibility in the cities of Taiwan. On the other hand, improvements in air quality supported the increase in visibility during the late 2000s and early 2010s. Our results show an almost exponential relationship between visibility and $\mathrm{PM}_{10}$. At lower PM 10 levels, the visibility is more sensitive to changes in the $\mathrm{PM}_{10}$. Thus, the influence of the long-term $\mathrm{PM}_{10}$ on visibility becomes weaker at high $\mathrm{PM}_{10}$ levels. Consequently, over the long term, the $\mathrm{PM}_{10}$ more strongly influenced the visibility trends at the northern urban stations, which had lower $\mathrm{PM}_{10}$ concentrations to begin with. At the southern urban stations, the $\mathrm{PM}_{10}$ concentrations were generally higher and hence were less of a factor in variations in visibility. Therefore, the visibility trends at these sites were more related to changes in $\mathrm{rH}$ until about 2011, at which time these regions reached a lower level of pollution.
\end{abstract}

Keywords: Visibility trends; Fog; Haze; $\mathrm{PM}_{10}$; Relative humidity.

\section{INTRODUCTION}

Both the scientific community and the public are concerned about atmospheric visibility. Although visibility can be reduced by natural meteorological conditions such as the formation of fog or cloud droplets under conditions of high air humidity, visibility is also a useful indicator of air pollution, as both gas molecules and particles in the air reduce visibility by light absorption and scattering. The conditions of air pollution in ambient air are complex and require careful and sophisticated analysis. Nevertheless, visibility can be useful as a proxy for air pollution because it is easily detected by the naked eye. According to the

\footnotetext{
* Corresponding author. Tel.: +49-176-99248268

E-mail address: maylin@maurer-stade.de

** Corresponding author.

Tel.: +49-251-83-33921, Fax: +49-251-83-38338

E-mail address: otto.klemm@uni-muenster.de
}

WMO (World Meteorological Organization, 1994, 2017), visibility (Vis) is defined as the greatest distance at which one can recognize either a black object during daylight or the light of a specified moderate intensity at night.

As a clear definition exists for visibility, definitions also exist to describe low-visibility events. For example, in accordance with the WMO's definition (World Meteorological Organization, 2014, 2017), fog is described in the literature as a condition in the near-surface atmosphere when the relative humidity $(\mathrm{rH})$ is near $100 \%$ and the horizontal visibility is reduced to less than $1 \mathrm{~km}$ due to the presence of small water droplets in the air. In addition, haze and mist are classified by the WMO as conditions with visibilities between $1 \mathrm{~km}$ and $5 \mathrm{~km}$. Depending on the ambient $\mathrm{rH}$, haze refers to visibility reductions caused by dry particles, whereas mist refers to visibility reductions caused by wet hygroscopic particles or small water droplets (World Meteorological Organization, 2014, 2017). To differentiate between haze and mist, the WMO uses a threshold of relative humidity at 95\% (World Meteorological Organization, 2014) or another "certain percentage" (e.g., 80\%; World Meteorological Organization, 2017). However, 
while the WMO definitions of haze and mist are rather straightforward, the definitions used in the literature are often not as consistent. Various studies have characterized haze and mist using different limits for the visibility range (e.g., Chung et al., 1999; Bruijnzeel et al., 2005; Vautard et al., 2009; Kuo et al., 2013; Akimoto and Kusaka, 2015), and the relative humidity level is often not even mentioned.

In this study, as we are interested in low-visibility events in general, we use the following definitions solely based on the observed visual range. From here on, conditions of restricted Vis between $1 \mathrm{~km}$ and $5 \mathrm{~km}$ are declared as haze. As we incorporated neither $\mathrm{rH}$ measurements nor the chemical composition of the aerosol particles, we did not further differentiate haze into the categories of haze and mist. Thus, haze in this study includes visibility reduction through both dry and wet particles as well as through small water droplets. Fog is, according to the WMO standard (World Meteorological Organization, 2014, 2017), defined as a condition with Vis below $1 \mathrm{~km}$. From here on, a foggy or a hazy day is a day during which fog or haze, respectively, was observed at least once. A single day may thus be a foggy day, a hazy day, both a foggy and a hazy day, or neither a foggy nor a hazy day.

During conditions of increasing $\mathrm{rH}$, aerosol particles in the ambient air may deliquesce, i.e., grow due to condensation of water vapor on them. Depending on the composition of the particles, the hygroscopic growth may be initiated at $\mathrm{rH}$ as low as $40 \%$ (for $\mathrm{NH}_{4} \mathrm{HSO}_{4}$ particles; Seinfeld and Pandis, 2016) and increases with the $\mathrm{rH}$ until $\mathrm{rH}=100 \%$, thereby affecting the aerosol's optical properties (Charlson et al., 1992; Cheng et al., 2008; Klemm and Lin, 2016). As a result, the visibility in a given air mass may decrease as $\mathrm{rH}$ increases from clear conditions to hazy conditions $(1 \mathrm{~km}<$ Vis $\leq 5 \mathrm{~km}$ ) and eventually to fog (Vis $\leq 1 \mathrm{~km})$ (Klemm and Lin, 2016). Once $\mathrm{rH}$ reaches supersaturation conditions slightly above $100 \%$, cloud condensation nuclei $(\mathrm{CCN}$, i.e., rather hygroscopic aerosol particles) can easily be activated and rapid growth to large fog droplet and eventually drizzle and rain becomes possible.

As the air temperature (T) is one of the drivers of $\mathrm{rH}$ via an inverse relationship, there is a rather direct link between $\mathrm{T}$ and $\mathrm{Vis}$ and thus a potential link between climate change and Vis: A temperature increase may, under otherwise constant conditions, decrease $\mathrm{rH}$ and thereby increase visibility. Another link between climate change and visibility exists through the sheer existence of water vapor in the air: If the water content in the air increases through increased evapotranspiration under otherwise constant conditions, $\mathrm{rH}$ increases and the visibility may be reduced.

At monitoring sites worldwide, numerous studies have detected an increase in visibility that occurs simultaneously with a decline in fog or haze (Sao Paolo: Gonçalves et al., 2008; California: LaDochy and Witiw, 2012; Poland: Bokwa et al., 2018; Europe: Vautard et al., 2009; Northern Eurasia: Ye, 2009; Japan: Akimoto and Kusaka, 2015). Such trends are observed especially in urban areas (e.g., Gonçalves et al., 2008; LaDochy and Witiw, 2012; Akimoto and Kusaka, 2015), but they can also occur in rural areas (e.g., Forthun et al., 2006). This visibility trend may be caused by the improvements in air quality that have occurred after the main peak periods of environmental pollution through industry (e.g., Avotniece et al., 2015; Bokwa et al., 2018), which resulted in a reduction of light scattering and light absorption by particles and lower concentrations of $\mathrm{CCN}$ in the atmosphere. However, as mentioned above, visibility is also affected by meteorological conditions such as air temperature and relative humidity. Therefore, in some cases the observed decrease in fog and increase in visibility is related to anthropogenic land use changes, reduced evapotranspiration due to sealing of soils and canalization of rain water, and to the urban heat island effect (e.g., LaDochy and Witiw, 2012). Yet in other cases, climate change has been argued to be the most important driver for increasing visibility because air temperatures are rising and relative humidity is decreasing (e.g., Ye, 2009). In general, all of these drivers likely contribute to the observed trends, and separating out the effects of each one is difficult (Klemm and Lin, 2016).

For some developing countries with increasing industrial activities and anthropogenic emissions, studies have reported that the trend is toward a decrease in visibility and an increase in the occurrence of hazy conditions. As an example, $\mathrm{Hu}$ et al. (2017) reveal an increase in the annual percentage of "bad visibility days" between 1973 and 2015 for three cities in India due to the population growth and ongoing emissions of coal and biomass combustion. In addition, Aldababseh and Temimi (2017) present a decreasing visibility trend in Abu Dhabi and Dubai during the period 1982-2016 resulting from synoptic and mesoscale climatic conditions in combination with recent land use changes.

As these different trends have been reported for various locations worldwide, we wanted to study how visibility has changed in Taiwan over time and what the drivers affecting visibility are. The climate in Taiwan, which is located to the southeast of the Chinese mainland, is subtropical in the north and more tropical in the south. The visibility conditions are influenced by the generally high relative humidity. Furthermore, Taiwan is densely populated with high industrial and agricultural activity, which is mainly situated in the western part of the island where the emissions of air pollutants are significant. In addition, emissions from mainland China and dust events may also influence Taiwan via long-range transport (Lin et al., 2004; Junker et al., 2009). This study aims to investigate trends in mean visibility and in the occurrence of fog and haze, as well as its spatial variation, in Taiwan. Since the meteorological and air chemistry datasets from this area reach back more than 30 years, a solid trend analysis is feasible.

\section{DATA AND METHODS}

\section{Data Sources and Site Description}

To analyze the trends and relationships between visibility, air quality and climate change, we evaluated data from ten different station pairs in Taiwan (Table S1). Meteorological data (from 1985 to 2016), such as Vis, T, rH and precipitation $(\mathrm{P})$, were provided by the Central Weather Bureau Taiwan (CWB) and originated from permanent 
stations. Each CWB station was matched with the closest air quality station of the Taiwan Environmental Protection Administration (EPA) that was exposed to similar environmental conditions. These stations are part of the Taiwan Air Quality Monitoring Network (TAQMN) and were mostly set up in September 1993. We obtained data on the pollutants sulfur dioxide $\left(\mathrm{SO}_{2}\right)$, nitrogen oxide $\left(\mathrm{NO}_{\mathrm{x}}\right)$ and particulate matter $<10 \mu \mathrm{m}$ in diameter $\left(\mathrm{PM}_{10}\right)$ from September 1994 to December 2016. The air quality data are publicly available and were downloaded from the EPA homepage (https://taqm.epa.gov.tw/taqm/en/YearlyDataDo wnload.aspx). Because most stations were set up on top of educational buildings ( $8 \mathrm{~m}$ to $20 \mathrm{~m}$ above ground level), we expect the measured concentrations to represent the local urban level of air pollution. The maximum linear distance between any pair of CWB and EPA stations is $11.4 \mathrm{~km}$ (between the stations of Puli and Jihyuehtan). Besides the comparability and closeness of station pairs, another important criterion for selecting the pairs was the availability of long-term data for both meteorological parameters and air pollution. Thus, trends in the data were analyzed for all the station pairs for which both visibility data were available from 1985 to 2016 and air quality data were available from 1994 to 2016.

The study sites are situated all over the island west of the mountain range (Fig. 1). One of the station pairs is on a small offshore island (Magong, MG) in the Taiwan Strait and is hence the closest one to mainland China (about $120 \mathrm{~km}$; Executive Yuan, Republic of China (Taiwan), 2014). Taiwan can be divided into two climate zones (Executive Yuan, Republic of China (Taiwan), 2014), the subtropical climate in the northern half of Taiwan and the tropical climate in the south of Taiwan; the transition zone is located in the middle of the island. Both the northern subtropical climate and the southern tropical climate are dominated by a monsoon flow from the NE in the winter and a southwesterly monsoon during the summer season. During the winter NE monsoon season, most of the southwestern part of Taiwan is located leeward of the dominating central mountain range and thus remains rather dry. Otherwise, i.e., during summer in the south and during the entire year in the central and northern parts, the climate is humid with rather large amounts of precipitation.

The Taiwan EPA stations are mostly located in urban

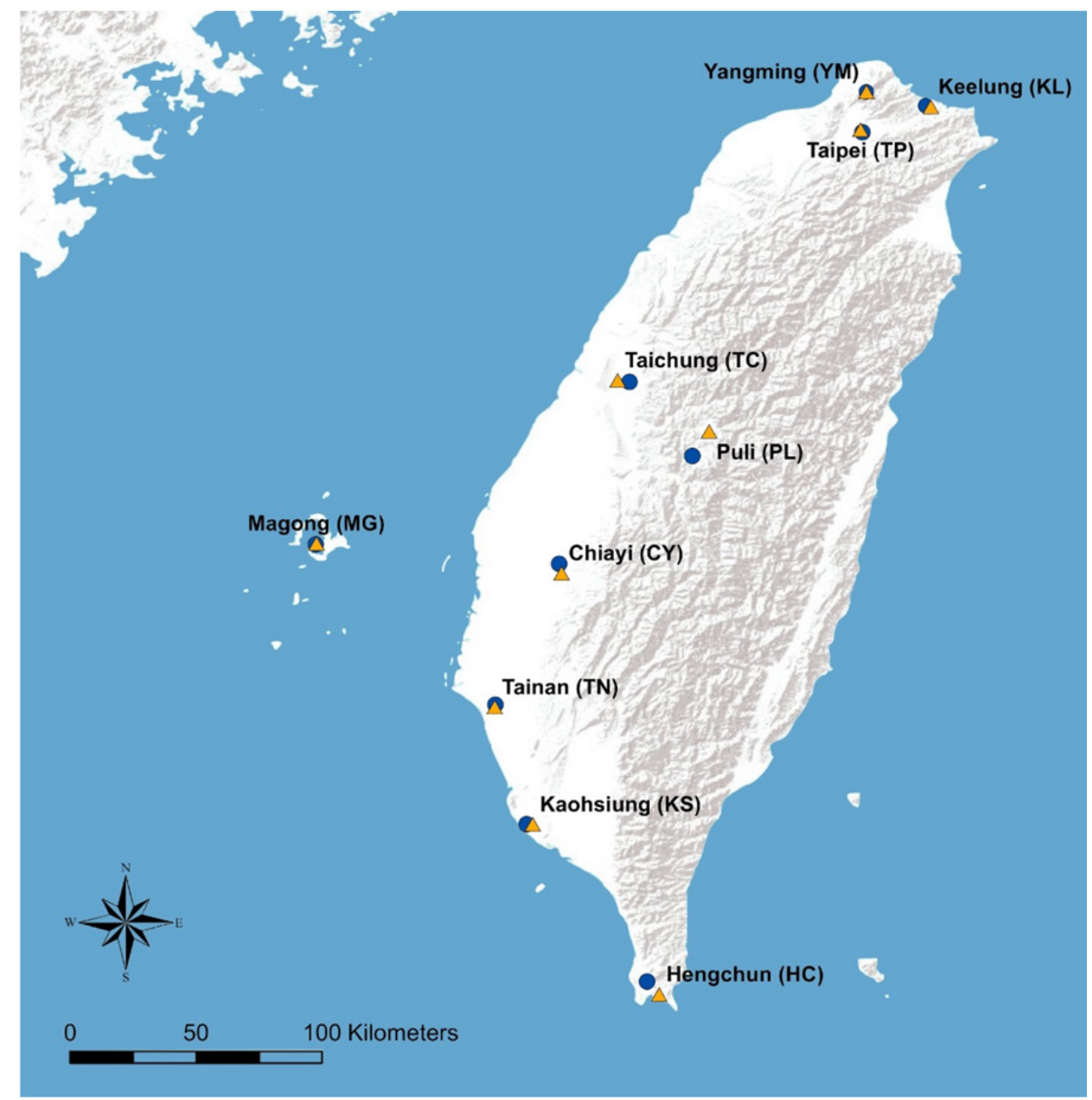

Fig. 1. Location map showing pairs of EPA air quality stations (orange triangles) and CWB weather stations (blue dots). The shading denotes the topography of the island. The map was created with ArcGIS® software by Esri using NOAA USGS data as a base map. 
areas so that our station pairs comprise only a few rural or background stations. Among all EPA stations, only Hengchun (HC) in the very south and Yangming (YM) in the very north can be classified as background stations. They are situated in Kenting National Park (HC) and Yangmingshan National Park (YM), respectively, with negligible direct influence from anthropogenic emissions. Accordingly, they are characterized as "national park stations" by the EPA. The so called "reference station" of the EPA in Puli (PL) is located in the center of the city of Puli in Nantou County within the central mountain range.

All other EPA stations are described as "general stations". Taipei (TP), Taichung (TC), Tainan (TN) and Kaohsiung (KS) are the most populous cities of Taiwan, with over one million inhabitants each. The cities' industries contribute a large share to the regional air pollution levels. Cities with large harbors, namely Keelung (KL) and especially Kaohsiung, are furthermore strongly affected by pollution from shipping. Chiayi (CY) and KL have under 500,000 habitants but are also impacted by industrial emissions and additionally by regional background air pollution from agriculture and industrial harbors, respectively. In contrast, Magong (MG) is a small offshore island with fewer local sources of air pollution.

\section{Measurements and Data Quality}

At the CWB, visibility is (and was) observed by human observers and is based on the standard observation procedure of the WMO (World Meteorological Organization, 2017). Buildings and fixed objects in the landscape with known distances from the station are referred to as target points. The visibility is observed at least eight times per day. To ensure comparability between all stations for our data analysis, only the eight observation hours that were consistent at all stations were included in the analysis (the intervals beginning at $04,07,08,10,13,16,19$, and 20 local time, which is UTC+8). We used these hours as filters for all parameters, including air pollution data from EPA stations in the later analysis. Meteorological data at six of the CWB stations (YM, KL, PL, CY, HC, and MG) were recorded at the same observation hours as visibility until the end of 1994; beginning in 1995, these data were recorded hourly by automatically operating instruments. For the other four stations (TP, TN, TC, and KS) the data were measured hourly from the beginning of the study period (1985). Data from the CWB was of good quality and contained almost no data gaps. For visibility data, only one month (June 1991) was missing for all stations, except for the fully complete visibility data in MG.

For most EPA stations, hourly air quality data are available for the time period starting from September 1993 (the beginning of the TAQMN measurements). At this time, the few stations that already existed were set to an identical technical standard. This change of instruments is evident in some of the datasets, causing us to reject from further analysis data collected before September 1993 at some stations. The second major instrument change for all EPA stations happened around 2004 and also had a remarkable impact on the magnitude of various parameters at a few stations. This instrument change resulted in abrupt changes in the standard deviation (Fig. 2(a)) or mean (Fig. 2(b)) of the affected data subsets, making these datasets unsuitable for

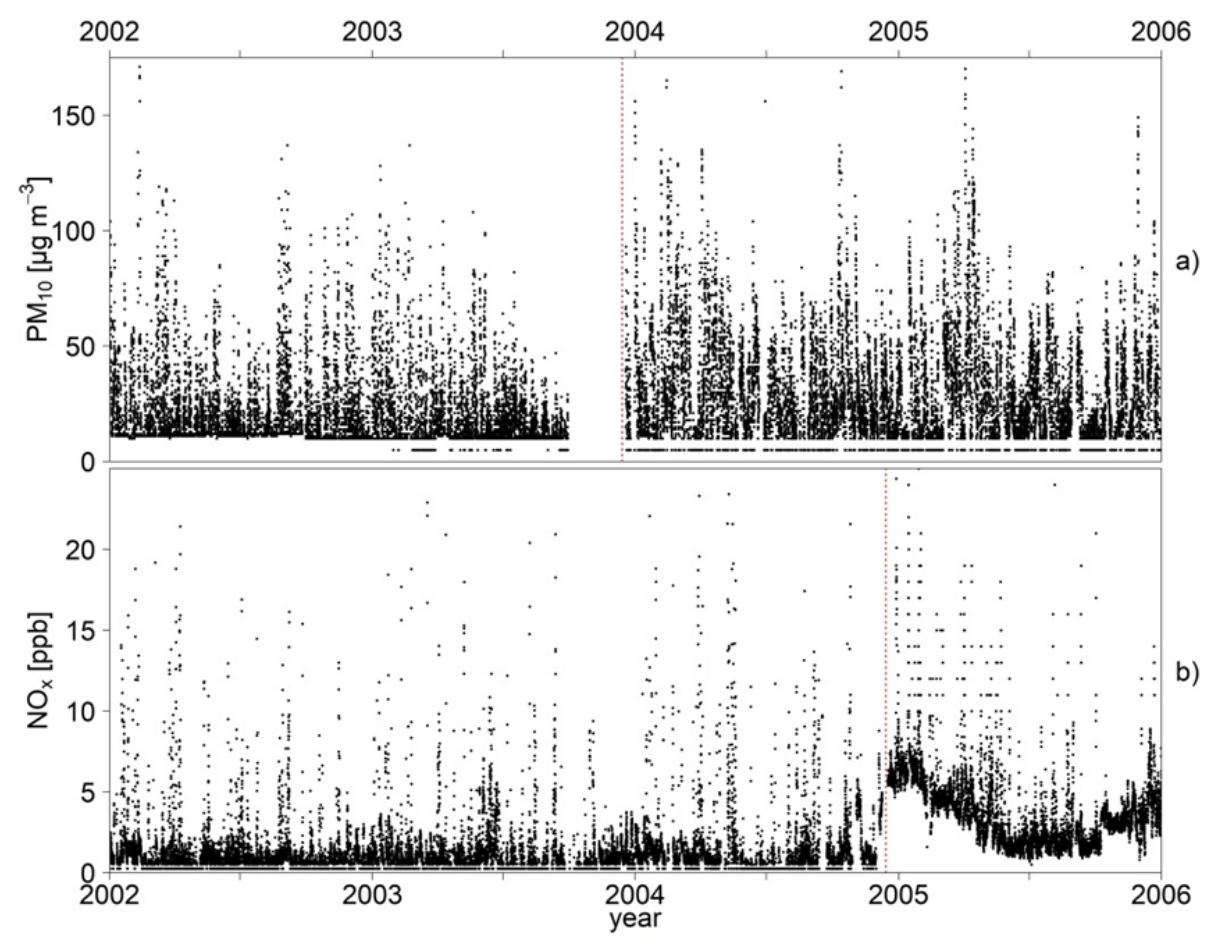

Fig. 2. Effect of instrument change on measured values. (a) Altered standard deviation of $\mathrm{PM}_{10}$ concentration in $\mathrm{YM}$ at the end of 2003 from $15.5 \mu \mathrm{g} \mathrm{m}^{-3}$ (previous year) to $22.2 \mu \mathrm{g} \mathrm{m}^{-3}$ (following year). (b) Higher mean mixing ratio of $\mathrm{NO}_{\mathrm{x}}$ in $\mathrm{HC}$ at the end of 2004 from $1.40 \mathrm{ppb}$ (previous year) to $3.71 \mathrm{ppb}$ (following year). 
computing trend statistics (Sulkava et al., 2007). In YM and $\mathrm{HC}$, the data before and after the change of hardware were not comparable, leading us to exclude these stations from subsequent trend and model analyses. In $\mathrm{TN}$, the $\mathrm{SO}_{2}$ concentrations changed abruptly for about six months to a higher mixing ratio, then suddenly returned to the former level. The affected time period from December 15, 2004, to May 31, 2005, was hence excluded from further analysis at this station.

The station pair near PL was excluded from air quality analysis because of a lack of comparability of the two stations' positions (large horizontal and altitudinal difference; see Table S1) and because of pronounced data gaps until April 2000. The air quality data of MG was not further analyzed because of late installation of the EPA station in 2004. Consequently, in total six of the ten station pairs underwent a more detailed long-term analysis that included potential drivers of low visibility.

\section{Data Analysis}

\section{Data Preparation}

All statistical analyses were performed using R 3.4.3 (R Core Team, 2017). Before applying any methods, quality control was performed on the raw data. With data exploration according to the methods of Zuur et al. (2010), we eliminated random errors, and we checked the values' ranges for physical plausibility and instrument-specified measuring ranges.

Our data analysis was performed on various time scales. The initial intention was to use yearly data (e.g., medians) for the Vis trends' driver analysis based on multiple linear regression models. However, this turned out to be impossible due to violation of the normality assumption for the residuals and the non-establishment of homoscedasticity. Therefore, only non-parametric linear trend analysis on single parameters was performed on the basis of yearly data. We used monthly and hourly values for comparative trend analysis and rank correlation analysis, respectively. For the purpose of a relative importance analysis based on a multiple linear regression model, we used daily medians because we aimed to use as large as possible yet equidistant (1-day) datasets. For that purpose, data gaps needed to be filled in order to obtain long and uninterrupted datasets.

In order to harmonize the meteorological and air chemistry data to those of Vis, we calculated the daily medians of all parameters on the basis of the Vis observation times ( 8 observations per day). For precipitation, we calculated the daily sums instead. The aggregation to daily values required at least $75 \%$ of valid hourly data, as proposed by the European Directive 2008/50/EC (European Parliament and Council of the European Union, 2008). Finally, as the air quality data in particular contained several data gaps, we applied a gap-filling routine (see Supplement).

\section{Trend Analysis}

In order to analyze trends in visibility at all stations, the annual mean of the original data (uniform hours) was used (Fig. 3). Additionally, the annual frequency of hazy days and foggy days was calculated. The trends' magnitudes (changes per year) resulted from linear regression trend analysis. Furthermore, the significance of trends was calculated with the non-parametric Mann-Kendall test (Mann, 1945; Kendall and Gibbons, 1990) using the R package "trend" (Pohlert, 2016, 2018). This method is more suitable for our data than the test statistic of the linear model, because the $t$-test (in this case equal to the $F$-test) requires normal distribution of the data.

In the comparative trend analysis, the trends of Vis, $\mathrm{T}$, $\mathrm{rH}$ and $\mathrm{PM}_{10}$ are presented for the six stations KL, TP, TC, CY, TN, and KS (Figs. S1 and S2). We extended the analysis with some important drivers of Vis, which are, at the same time, variables of climate change ( $\mathrm{T}$ and $\mathrm{rH}$ ) and air quality $\left(\mathrm{PM}_{10}\right)$. In addition to analyzing the trends of the entire time series, the magnitudes of trends for 10 -year sub-periods were estimated through linear regression models (Table S2). For these analyses, the monthly median data were used to provide insight into seasonal variations as well. The seasonal Mann-Kendall test was employed to quantify the level of significance of these trends (Hirsch et al., 1982; Hipel and McLeod, 1994). The shown trend lines were computed using a Singular Spectrum Analysis (SSA; see Supplement). We applied the SSA on the monthly median data and included only the first eigenvalue to show the underlying trend after the removal of all seasonal and other regular or random variations (chosen window length of 74).

\section{Analysis of Visibility and Related Parameters}

A statistical driver analysis was performed for the six stations and the period from September 1993 to December 2016.

Our first focus within the driver analysis was on the general relationship of daily visibility, meteorological parameters and air quality. For a quick impression, we performed a correlation analysis. On the basis of original hourly data, we determined the Spearman rank correlation coefficient between visibility on the one hand and each affecting variable on the other. We used the non-parametric Spearman rank correlation because of its applicability to non-normally distributed data.

Afterwards, we wanted to identify the main drivers of low-visibility conditions and each driver's individual importance to the variations in visibility. Therefore, the relationship between visibility and its affecting parameters was analyzed based on multiple linear regression models using daily median data. We included explanatory variables representing the air pollution $\left(\mathrm{PM}_{10}, \mathrm{SO}_{2}\right.$, and $\left.\mathrm{NO}_{\mathrm{x}}\right)$, meteorology ( $\mathrm{T}, \mathrm{rH}$, and $\mathrm{P}$ ) and seasonality (day of the year). To fulfill the normality condition of residuals, the response variable (visibility) was transformed. The logarithm of visibility was set as the response variable in the model for all stations except Keelung (KL), where the square root of visibility was used instead.

The constructed multiple linear regression models served as input for the relative importance analyses using the $\mathrm{R}$ package "relaimpo" (Grömping, 2006) with the lmg method proposed by Lindeman, Merenda and Gold (Lindeman et $a l ., 1980)$. The relative importance of explanatory variables is 

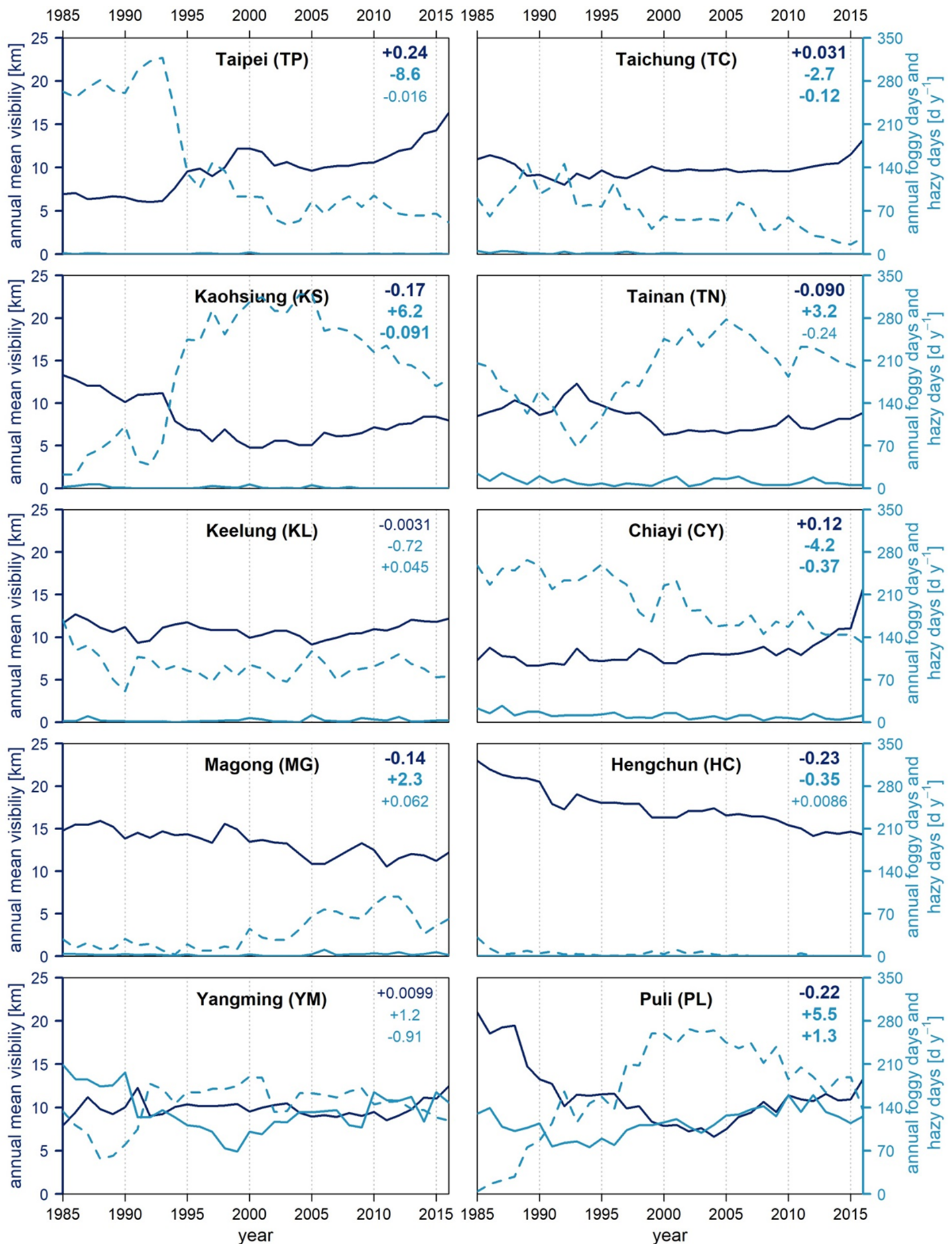

Fig. 3. Time course of the mean annual visibility (dark blue line) and annual sum of hazy days (bright blue dashed line) and foggy days (bright blue solid line) at all stations included in the studies. The numbers in the upper right corner of the chart denote the linear change trends of the mean annual visibility $\left[\mathrm{km} \mathrm{y}^{-1}\right]$, hazy days $\left[\mathrm{d} \mathrm{y}^{-2}\right]$ and foggy days $\left[\mathrm{d} \mathrm{y}^{-2}\right]$, topdown. Bold font indicates the trend's significance at a 95\% confidence level performed with the Mann-Kendall test. 
defined as the individual predictor's contribution to the multiple regression model (Grömping, 2006). The advantage of this method is that it is specifically suited to correlated explanatory variables. In those cases, the computed influence of a variable on the visibility differs depending on additionally included predictor variables and their order. Likewise, the variable's contribution to the explained variance $\left(\mathrm{R}^{2}\right)$ changes. Therefore, all possible combinations of the multiple linear regression model (the number of included variables and their order) are included in the relative importance analysis, and the parameter's contribution to each model's $\mathrm{R}^{2}$ is calculated. Finally, the parameter's individual relative importance in the overall model is computed by unweighted averaging over all those contributions. The added benefit of doing the relative importance analysis rather than just the correlation analysis is that we can estimate each factor's contribution to the total amount of variation in visibility during the study period at a certain station.

The second purpose of the driver analysis was to study the long-term response of visibility to its main drivers, as calculated in the relative importance analysis. We extended the temporal time steps to monthly data and conducted the comparative trend analysis (as described above). To better understand the relationship between $\mathrm{PM}_{10}$ and visibility while comparing the trends of the different parameters, we additionally visualized the relation between the two in a scatterplot.

\section{RESULTS AND DISCUSSION}

\section{Long-term Visibility Trends of Ten Sites}

The time courses of the mean annual visibility and the occurrence of fog and haze at all ten stations under investigation (Fig. 3) provide an overview of the entire study period from 1985 through 2016. The development varies largely between stations, indicating there is no uniform trend. The overall linear trends in visibility range from $-0.23 \mathrm{~km} \mathrm{y}^{-1}$ (HC) to $+0.24 \mathrm{~km} \mathrm{y}^{-1}$ (TP). At some sites (e.g., KL and YM), no clear trend can be observed at all. Although there is no consistent pattern for all stations, we do see a consistent increase in visibility and decrease in the frequency of haze in the most recent 5 to 10 years at most of the stations, except for the rural to suburban regions of $\mathrm{HC}$ and MG.

\section{Mountain Sites}

The CWB station of PL, located on top of Mt. Maolan, is isolated from direct local anthropogenic impact. However, some touristic and agricultural activities are present in the region. The decrease in mean visibility up to 2004 is accompanied by a coincident increase in hazy conditions. After 2004, both trends change, such that the visibility increases and the number of hazy days decreases. Because of the change in the direction (the sign) of the trends, it does not seem plausible that this was directly caused by climate change, which is an ongoing process. However, the observed changes in visibility and haze may have been caused by an initial increase and then a later reduction of advection or accumulation of air pollution. A synchronous change in the frequency of foggy days did not occur at PL. Instead, a positive trend of $+3.6 \mathrm{~d} \mathrm{y}^{-2}(99 \%$ significance level) was found in the period 1991-2012. Fog at this altitude (1001 $\mathrm{m}$ asl) can be classified as mountain fog, which is orographically controlled (Bruijnzeel et al., 2005), or an advected stratus cloud. The increase of foggy days in the period 1992-2012 and hazy days in 1985-2004 may be explained by indirect effects of climate change. On the one hand, a higher frequency of fog at a given site could be evoked by a regional increase in evapotranspiration caused by rising air temperatures. Clouds and mountain fog are formed by the condensing of humid air masses from lower altitudes due to adiabatic cooling as they are uplifted to higher altitudes. If increased evapotranspiration at the lowlands causes the original air masses to contain more humidity, then the cloud condensation level may be shifted to a lower altitude asl, thus leading to a higher frequency of fog at these altitudes. On the other hand, it is possible that global and regional warming could shift the cloud base upward, such that a high-altitude station that was previously often above the clouds is now located closer to the central cloud height and is thus more affected by advected mountain fog. Increased concentrations of anthropogenic aerosols, acting as $\mathrm{CCN}$, can also contribute to a positive trend in cloud formation.

The second mountain station, YM (833 m asl), is exposed to comparable environmental conditions, except it is located in the northernmost part of Taiwan. The mean visibility at YM shows no significant trend at all. However, the frequencies of foggy and hazy conditions follow opposite patterns. Specifically, the fog frequency decreased until 1999 and then increased afterward, while the haze frequency shows almost the exact opposite pattern: it increased until 2001 and then decreased afterward. For the trends at both mountain stations, PL and YM, similar conditions and processes are relevant. Currently, we cannot identify one single factor determining the fog and haze trends but only propose potential influencing factors and processes. A more detailed driver analysis for the entire study period could not be performed because of deficient data on air pollution due to the change of measurement techniques at the end of 2003 in YM and due to substantial data gaps until 2000 in PL.

\section{Rural and Suburban Lowland Sites}

At $\mathrm{MG}$ and $\mathrm{HC}$, low-visibility events are rare in comparison with the other stations (on average, $21 \mathrm{~d} \mathrm{y}^{-1}$ of haze and $1.4 \mathrm{~d} \mathrm{y}^{-1}$ of fog for 1985-2016). Both stations are the only ones with nearly continuous decreases in the mean visibility. Besides PL, these stations started at the highest level of visibility for all stations in 1985. Without industrial activities nearby, they are less impacted by local air pollution. Ambient air pollution (especially $\mathrm{PM}_{10}$ ) in $\mathrm{MG}$ thus mainly results from emissions by industrial centers in mainland China as well as from coastal regions of the Korean Peninsula and islands of Japan (Lin et al., 2004; Li et al., 2015). Similarly, the HC monitoring station is located in clean background air, about $80 \mathrm{~km}$ to the nearest 
industrial center in Kaohsiung (Tsai et al., 2015). While the aerosol composition in this region is strongly affected by sea-land breezes, long-range transport from anthropogenic emissions and biomass burning products (from Southeast Asia) may contribute temporarily as well (Tsai et al., 2012; Lin et al., 2013; Tsai et al., 2015). Additionally, Junker et al. (2009) analyzed backward trajectories of the sampling period 1993-2006 in HC, and they found that the majority $(62 \%)$ of air masses had travelled over Japan, Korea or northern China, while only a negligible fraction had passed over Taiwan before arriving at HC. Altogether, MG and $\mathrm{HC}$ exhibit a decreasing trend in mean visibility at stations with fewer local pollution sources. The drivers of these trends are not clear at this point. Increased long-range air pollution may be a possible explanation and could be boosted by a slow increase in local air pollution (e.g., higher traffic density). Likewise, an influence from climate change seems plausible. Higher evapotranspiration due to increasing temperatures could have led to increased relative humidity and thereby reduced visibility. However, as was the case for the mountain stations, these data were also not sufficient for further long-term analyses. Another study by Tsai et al. (2007) also detected trends of declining visibility in two rural areas in eastern Taiwan (Hualien and Taitung) for the period 1961-2003. They argue that increases in local traffic emissions and long-range transport may be important influencing factors.

\section{Urban Lowland Sites}

All other stations (KL, TP, TC, CY, TN, and $\mathrm{KS}$ ), located in urban or even industrial areas, are potentially more heavily influenced by local air pollution and are affected by periodic accumulation events (Lin et al., 2004). Particularly in winter, during stable atmospheric conditions with cold air, high pressure and low wind speeds, pollution is not as well dispersed and instead accumulates in its source region. Under these conditions, high concentrations of air pollutants can be reached and result in typical hazy situations with reduced visibility (Lin et al., 2004; Tsai, 2005; Deng et al., 2014). Therefore, the frequency of haze is generally higher at these sites (on average, $149 \mathrm{~d} \mathrm{y}^{-1}$ for 1985-2016).

In addition, long-range transport is an important source of air pollution, particularly for $\mathrm{PM}_{10}$ and during winter and spring at the sites in northern Taiwan (Lin et al., 2004). Northeasterly winds advect dust and other air pollutants from Asia to the island of Taiwan during frontal passages of the winter monsoon. As a result, the visibility is reduced, and haze is induced.

The trends at the urban stations vary due to their specific locations and the development of the cities in the past 32 years. The inland sites, CY, TC, and TP, exhibit a significantly increasing mean visibility and a synchronously declining frequency of haze and fog (not significant for TP) over the 32-year period. While CY and TC show a slight, nearly continuous decrease of haze, the change at TP is more drastic, with a strong drop in the number of hazy days between 1993 and 1995. The mean frequency of haze in the period 1985-1994 $\left(285 \mathrm{~d} \mathrm{y}^{-1}\right)$ was about three times higher than in later years $\left(84 \mathrm{~d} \mathrm{y}^{-1}\right)$. We will discuss this phenomenon further in the section "Comparative Trend Analysis". In contrast, the major cities in the south (KS and TN) show an overall decreasing trend in mean visibility, which can be divided into a decline from 1985 to about 2000 and a following increase from 2005 to 2016. During the period in between (2000-2005) with notably low visibility, the frequency of hazy days reached its maximum at both stations. For KS, the maximum percentage of hazy days was $87 \%$ (320 days of haze in 2004), which was the highest of all stations in the entire study period. However, foggy days were rare in KS and slightly declined over the study period. In contrast, the fog frequency in TN remained at a moderate level (on average, $10.6 \mathrm{~d} \mathrm{y}^{-1}$ ) during the whole period and shows no trend. At KL, a smaller city on the northern coast of Taiwan, the mean visibility and the frequency of low-visibility events show no significant trend over the entire study period.

Our analysis of causes for the visibility trends at the urban stations (KL, TP, TC, CY, TN, and KS), taking into context climate change and air quality, is shown later (in the section "Comparative Trend Analysis").

\section{Visibility and Related Factors at Six Urban Sites}

In this section, we performed a driver analysis for the six urban stations (KL, TP, TC, CY, TN and KS) over the period from September 1993 to December 2016 to determine the general factors affecting visibility (correlation analysis) and their importance to the visibility variations (relative importance analysis) observed in these cities. For a closer look, the analyses were conducted in higher temporal resolution. Detailed analyses for $\mathrm{HC}, \mathrm{MG}, \mathrm{YM}$ and $\mathrm{PL}$ were not performed because of insufficient data quality.

\section{Correlation Analysis}

First, analyses of the relationship between visibility and both meteorological factors and pollutant concentrations were performed with Spearman's rank correlation on the basis of the original hourly data. Results are presented in Table 1 (" $\rho$ " columns). The directions of the relationships (i.e., the signs of $\rho$ ) are the same for each meteorological factor at all stations, whereas the strengths vary. All correlations are significant at the $99 \%$ confidence level.

$\mathrm{V}$ is is positively correlated with $\mathrm{T}$. Warmer air masses can hold more water vapor, which leads to lower $\mathrm{rH}$ at higher temperatures but identical water vapor concentrations in the air. Accordingly, droplets evaporate, which leads again to an increase in $\mathrm{rH}$ yet lower liquid water content (LWC) in the air (Klemm and Lin, 2016).

Correspondingly, $\mathrm{rH}$ has a negative correlation with Vis. With high $\mathrm{rH}$, hygroscopic aerosol particles start deliquescing and grow in diameter, which leads to higher extinction coefficients due to Mie scattering (Klemm and Lin, 2016). Additionally Zhang et al. (2015) as well as Tsai and Cheng (2004) found that the chemical conversion rate from gasphase precursor gases (e.g., $\mathrm{SO}_{2}$ and $\mathrm{NO}_{\mathrm{x}}$ ) to particlephase constituents $\left(\mathrm{SO}_{4}{ }^{2-}\right.$ and $\left.\mathrm{NO}_{3}{ }^{-}\right)$increases under high humidity conditions, i.e., the formation of secondary particles is accelerated. This process amplifies the visibility reduction 
Table 1. Results of driver analyses for visibility in KL, TP, TC, CY, TN, and KS for 09/1993-12/2014. Spearman's rank correlations $(\rho)$ between visibility and shown variables are based on original hourly data. All calculations of $\rho$ are significant at the $99 \%$ confidence level. The relative importance (RI) represents every predictor's contribution to the sum of explained variance $\left(\mathrm{R}^{2}\right)$ of a multiple linear model of daily data.

\begin{tabular}{|c|c|c|c|c|c|c|c|c|c|c|c|c|}
\hline \multirow{2}{*}{ Variable } & \multicolumn{2}{|c|}{ Keelung (KL) } & \multicolumn{2}{|c|}{ Taipei (TP) } & \multicolumn{2}{|c|}{ Taichung (TC) } & \multicolumn{2}{|c|}{ Chiayi (CY) } & \multicolumn{2}{|c|}{ Tainan (TN) } & \multicolumn{2}{|c|}{ Kaohsiung (KS) } \\
\hline & $\rho$ & $\mathrm{RI}[\%]$ & $\rho$ & RI [\%] & $\rho$ & RI [\%] & $\rho$ & $\mathrm{RI}[\%]$ & $\rho$ & RI [\%] & $\rho$ & RI [\%] \\
\hline Day of the year & & 10.2 & & 7.36 & & 9.76 & & 13.4 & & 19.2 & & 13.8 \\
\hline Temperature & 0.413 & 8.95 & 0.328 & 5.68 & 0.261 & 1.69 & 0.481 & 7.48 & 0.547 & 9.72 & 0.518 & 7.52 \\
\hline Rel. humidity & -0.540 & 23.8 & -0.440 & 18.7 & -0.307 & 13.0 & -0.269 & 9.43 & -0.270 & 5.69 & -0.0963 & 3.45 \\
\hline Precipitation & -0.516 & 7.90 & -0.359 & 3.53 & -0.219 & 1.83 & -0.0605 & 0.416 & -0.102 & 1.07 & -0.100 & 1.16 \\
\hline $\mathrm{PM}_{10}$ & -0.162 & 4.57 & -0.280 & 13.2 & -0.429 & 17.7 & -0.581 & 17.9 & -0.517 & 14.1 & -0.600 & 20.6 \\
\hline $\mathrm{SO}_{2}$ & -0.114 & 1.11 & -0.185 & 5.10 & -0.226 & 4.22 & -0.374 & 4.58 & -0.155 & 2.25 & -0.236 & 1.96 \\
\hline $\mathrm{NO}_{\mathrm{x}}$ & -0.130 & 1.32 & -0.204 & 4.09 & -0.334 & 5.68 & -0.521 & 8.18 & -0.364 & 3.98 & -0.471 & 9.17 \\
\hline $\operatorname{Sum}\left(R^{2}\right)$ & & 57.9 & & 57.6 & & 53.8 & & 61.4 & & 56.0 & & 57.7 \\
\hline
\end{tabular}

due to an even higher extinction coefficient (Sabetghadam and Ahmadi-Givi, 2014). Preduces the horizontal visual range through light scattering by the raindrops (Lin et al., 2010).

The air pollutants $\mathrm{PM}_{10}, \mathrm{SO}_{2}$, and $\mathrm{NO}_{\mathrm{x}}$ show negative correlations with Vis. On the one hand, aerosol particles directly impair the visibility through light scattering and absorption (Hand, 2011). On the other hand, serving as $\mathrm{CCN}$, hygroscopic aerosols contribute to the formation of fog and mist. Therefore, the reduction of visibility by $\mathrm{PM}_{10}$ depends on the chemical composition of the ambient aerosols. Note additionally that the mass and number distributions within the size range of dry particles can be manifold. While the particle mass concentration of $\mathrm{PM}_{10}$ is dominated by a relatively small number of large particles, the visibility is mostly influenced by the number concentration of smaller particles with diameters around $1 \mu \mathrm{m}$ (SabbaghKupelwieser et al., 2010; Klemm and Lin, 2016). The analysis of the relationship between $\mathrm{PM}_{10}$ and visibility is hence difficult and contains large uncertainties. Nevertheless, strong correlations between $\mathrm{PM}_{10}$ and Vis can be found in this study as well as in related work (e.g., Tsai et al., 2003; Tsai, 2005; Deng et al., 2014; Sabetghadam and AhmadiGivi, 2014). The gaseous pollutants $\mathrm{SO}_{2}$ and $\mathrm{NO}_{\mathrm{x}}$ have only a marginal direct impact and affect visibility particularly through their function as precursor gases for secondary particles. These may act as CCN and are often mentioned as important drivers of low-visibility events (Yuan et al., 2006; Cao et al., 2012; Zhang et al., 2016). The comparatively low correlations in our analysis are probably due to their accelerated conversion into the particle phase under high humidity conditions (see above). During low-visibility events, these pollutants are hence proportionally less present in the measured gas phase and more present in the particle phase (Tsai and Cheng, 2004; Zhang et al., 2015).

\section{Relative Importance Analysis}

Afterwards, we conducted the relative importance analysis for the same parameters and an additional seasonality component, "day of the year" (DoY), using daily median data. By calculation of the parameters' contributions to the total variance in the Vis, we detected the most important drivers for daily visibility variations. The results of the relative importance analysis are shown in Table 1 ("RI" columns). Overall, the most important factors explaining Vis variations are the seasonality (DoY), $\mathrm{PM}_{10}, \mathrm{~T}$ and $\mathrm{rH}$. The contributions of these main drivers are additionally depicted in Fig. 4. The results of the correlation analysis between Vis and the respective parameters, as presented in Table 1 as well (" $\rho$ " columns), are mostly confirmed by the results of the relative importance analysis.

The underlying multiple linear models explain $54 \%$ to $61 \%$ of the Vis data's variance $\left(R^{2}\right)$, i.e., $39 \%$ to $46 \%$ of the variance in the Vis remains unexplained. A possible reason for this relatively low proportion of the variance being explained might be the uncertainty in analyzing the relationship between visibility and air pollution. As outlined in the previous section, "Correlation Analysis", the $\mathrm{SO}_{2}$ and $\mathrm{NO}_{\mathrm{x}}$ concentrations as well as $\mathrm{PM}_{10}$ are major components of air pollution, but they are not perfect predictors for how air pollution influences visibility.

Lying in urban or even industrial areas, the six stations are exposed to heavy local air pollution. Therefore, $\mathrm{PM}_{10}$ is in general one of the most important variables explaining the variations in the visibility's daily median at the urban stations (13-21\%), except at KL (5\%). The gaseous pollutants $\mathrm{SO}_{2}$ and $\mathrm{NO}_{\mathrm{x}}$ contribute only $1-9 \%$ of the total variance in the Vis (not shown in Fig. 4; see Table 1).

The meteorological parameters $\mathrm{P}$ and $\mathrm{rH}$ show decreasing importance from north to south. As compared to the southern section of the island, northern Taiwan is affected by frequent rainfall throughout the entire year and is especially impacted by the NE monsoon in winter. Therefore, the variance in the Vis at the northern stations KL and TP is strongly influenced by P. By contrast, southwestern Taiwan is relatively dry (primarily in winter), and the relative importance of $\mathrm{P}$ as a driver of Vis variations is accordingly low. This strong contrast between the north and south is reported as well by Tsai et al. (2007). They detected a remarkable difference in rain frequency between Taipei and Kaohsiung, which led to a stronger overall reduction in visibility by rain in Taipei. Results from Tsai (2005) in Tainan support this thesis. Regarding rH, this variable is the dominant contributor to the explained variance in the Vis at the two northern stations Keelung and Taipei (24\% and 19\%, respectively). Similar to $\mathrm{P}, \mathrm{rH}$ 


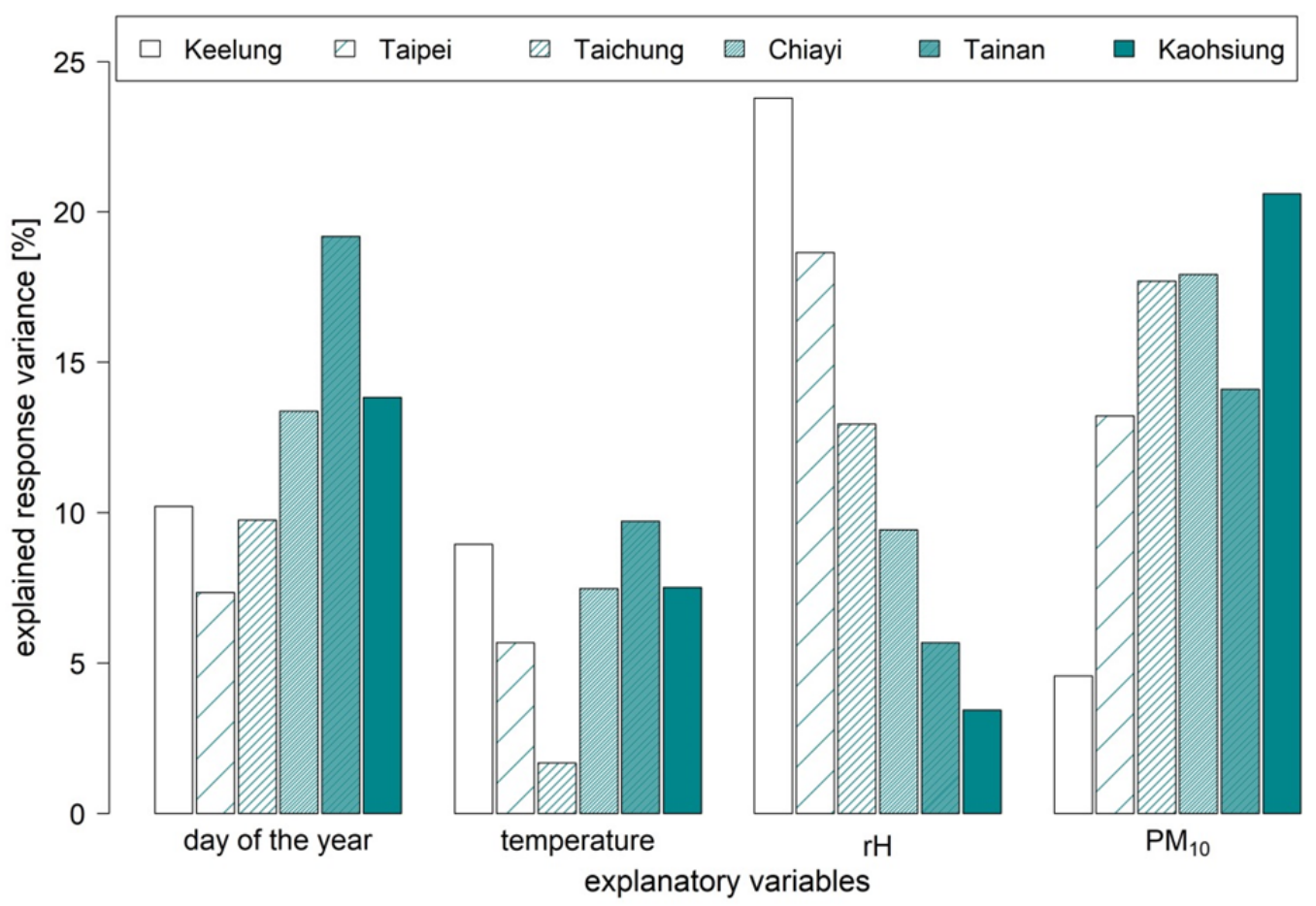

Fig. 4. Results of the relative importance analysis, showing only the main drivers of visibility. Bars illustrate the driver's contribution to the model's $\mathrm{R}^{2}$.

also shows a clear decrease in importance from north to south (Fig. 4). In the subtropical north, $\mathrm{rH}$ exhibits strong variations with peaks in the winter season (Fig. S1). By contrast, the general variability of $\mathrm{rH}$ in the tropics is less pronounced and exhibits almost no seasonality at all (TN and $\mathrm{CY}$ ) or even opposite seasonal variations, with higher $\mathrm{rH}$ in summer (KS) (Fig. S2). The $\mathrm{rH}$ at the southern sites varies less and consequently exerts less influence on Vis. This is reflected by the lesser relative importance of $\mathrm{rH}$ at the southern sites compared to the northern ones.

The differing importance of $\mathrm{T}(2-10 \%)$ may possibly be explained by the urban heat island effect (UHI). In bigger cities, the wind field is modified, and the mean wind speed is reduced, which causes less mixing of the air masses in an urban environment. In addition, the buildings store heat energy rather effectively, which leads to diminished variation in $\mathrm{T}$ within the cities. Therefore, the stations TC and TP, which are both located in the centers of big cities, are likely exposed to a stronger UHI and thus to less variation in $\mathrm{T}$. This may diminish the relative importance of $\mathrm{T}$ as a driver of Vis. Furthermore, the stations $\mathrm{TN}$ and $\mathrm{KS}$ are located closer to the shore and therefore exhibit larger effects from sea-land breezes and thus potentially larger variations of $\mathrm{T}$ as well. In these cities, $\mathrm{T}$ is a more important variable for explaining Vis. As the UHI is less pronounced in smaller cities, the variations of $\mathrm{T}$ and their importance to Vis are potentially larger in CY and KL.

On average, the relative importance of the parameter DoY is one of the largest ( $7.4 \%$ for TP to $19 \%$ for $\mathrm{TN})$. Vis in Taiwan is usually lower during the winter months (Figs. S1 and S2). This seasonality of Vis is somewhat more pronounced at the southern stations of $\mathrm{CY}, \mathrm{TN}$ and
KS. At these stations, the high mean air pollution exhibits strong seasonal fluctuations with peaks in the winter seasons (cf. $\mathrm{PM}_{10}$ in Fig. S2) and thereby induces opposite seasonal fluctuations in Vis. By contrast, at northern sites (KL, TP and TC), the seasonality of the generally lower air pollution is less pronounced (Ding et al., 2016), whereas $\mathrm{rH}$ exhibits stronger seasonal variance. The fluctuations in Vis throughout the year arise from the combined effects of both factors and are consequently less regular overall. This becomes evident through the lesser relative importance of the parameter DoY in explaning Vis at the northern stations.

\section{Comparative Trend Analysis at Six Urban Stations}

Given the results presented in the previous sections, we subsequently examined the drivers and relationships influencing the long-term changes in visibility at the urban sites (KL, TP, TC, CY, TN and KS). Therefore, in Figs. S1 and S2 the trends of Vis (see the section "Long-term Visibility Trends") were compared with those of the most important drivers of $\mathrm{V}$ is $\left(\mathrm{T}, \mathrm{rH}\right.$, and $\mathrm{PM}_{10}$, as determined in the section "Visibility and Related Factors") for each of the urban stations. Analyses used monthly median data to provide insight into seasonal dependencies. In addition, the means, standard deviations $(\sigma)$ and trends for sub-periods were calculated for a more detailed comparison (Table S2).

\section{Climate Change and Air Quality Improvement in Urban Taiwan}

All trends for the entire period (1985-2016) are significant at a 95\% confidence level. $\mathrm{T}$ increases (on average, $+0.035^{\circ} \mathrm{C} \mathrm{y}^{-1}$ ) and $\mathrm{rH}$ decreases (on average, $-0.125 \% \mathrm{y}^{-1}$ ) at all stations. These trends of $\mathrm{T}$ and $\mathrm{rH}$ are probably 
induced by climate change and the ongoing urbanization of the six cities, i.e., the UHI and reduced evapotranspiration due to the sealing of soils and canalization of rain water. As $\mathrm{PM}_{10}$ data was only mostly available starting in 1993, trends could not be computed for the entire 32-year period at all stations. However, it becomes evident from the depicted time courses and trends in the sub-periods that Taiwan experienced a large improvement in air quality. Governmental regulations in Taiwan started with the Air Pollution Control Act (APCA) in 1975, but they became effective only after 1992, when stricter rules were implemented (Tang, 1993). The accompanying monitoring (by TAQMN, beginning in September 1993) plus the implementation of emission standards for power plants in 1994 (EPA Air 12812) have been crucial initial steps for the reduction of anthropogenic emissions. Several further air quality standards regulating vehicular and industrial emissions became effective and contributed to the strong decrease in emissions starting in 1994 (Chen et al., 2014). In addition, the Environmental Protection Law in mainland China, implemented in 1989, led to emission reductions starting in 2006 (Lin et al., 2012; Jin et al., 2016). This likely had a positive influence on Taiwan's air quality, as long-range transport is a significant source of air pollution (especially $\mathrm{PM}_{10}$ ) at most sites in northern Taiwan (Lin et al., 2004; Chan and Chan, 2017).

\section{Long-term Response of Visibility}

Due to several combined factors, e.g., aerosol composition and size distribution (see the section "Correlation Analysis") as well as the Twomey effect (i.e., the optical thickness of a cloud is sensitive to the density of particles serving as CCN; Twomey, 1991), the relationship between Vis and $\mathrm{PM}_{10}$ mass concentration is not linear but is instead almost exponential. Fig. 5 shows a scatterplot of Vis versus $\mathrm{PM}_{10}$ for all available monthly data. Vis decreases rapidly with increasing $\mathrm{PM}_{10}$ concentrations up to about $70 \mu \mathrm{g} \mathrm{m}^{-3}$, but it decreases much more slowly at higher $\mathrm{PM}_{10}$ concentrations.
We presume that when $\mathrm{PM}_{10}$ concentration levels are high (e.g., in the heavily polluted cities $\mathrm{CY}, \mathrm{TN}$, and $\mathrm{KS}$ ), the long-term decline in $\mathrm{PM}_{10}$ exhibits only a marginal influence on the visibility. In contrast, for sites with initially lower $\mathrm{PM}_{10}$ concentration levels (e.g., in KL, TP, and TC), longterm changes in $\mathrm{PM}_{10}$ concentrations lead to stronger responses in visibility. Therefore, the $\mathrm{PM}_{10}$ reduction during the entire study period, which was detected at all urban stations, had a strong impact on the visibility in the northern cities (Fig. S1), whereas these improvements in air quality only started having an effect on the visibility in the southern cities in the last few years, once they had reached a generally lower level of pollution (Fig. S2). This may explain the consistent significant positive trend of Vis in the last 5 to 10 years occurring at all urban stations (on average, $+0.3 \mathrm{~km} \mathrm{y}^{-1}$ for 2005-2016) after better air quality was reached. The influence of long-term changes in $\mathrm{rH}$ are more evident in the southern, more polluted regions. Vis trend lines in $\mathrm{TN}, \mathrm{KS}$ and $\mathrm{CY}$ progress in almost opposite directions compared to those of $\mathrm{rH}$. The influence of $\mathrm{rH}$ changes at the northern stations (e.g., TP; Fig. 6) are less apparent because of its combined effects with the strong influence of $\mathrm{PM}_{10}$.

TP serves as an exemplary station with a comparatively low $\mathrm{PM}_{10}$ concentration level (average of $42 \mu \mathrm{g} \mathrm{m}^{-3}$ for 1995-2016), and it is depicted in Fig. 6. At TP, Vis exhibits a strong response to changes in $\mathrm{PM}_{10}$. The great improvements to air quality made since the establishment of the Taipei Mass Rapid Transit System in 1996 (Executive Yuan, Republic of China (Taiwan), 2014; Ding et al., 2016) induced a remarkable increase in Vis. Later increases of $\mathrm{PM}_{10}$ from 2001 to 2006 and the following strong decrease most likely led to a clear response in Vis. Additional influence results from the overall increase in $\mathrm{T}$ (on average, $+0.034^{\circ} \mathrm{C} \mathrm{y}^{-1}$ ) and nearly continuous decrease in $\mathrm{rH}$ (on average, $-0.13 \% \mathrm{y}^{-1}$ ), which have certainly supported the total increase in Vis at the TP site (on average, $+0.27 \mathrm{~km} \mathrm{y}^{-1}$ ) from 1985 to 2016.

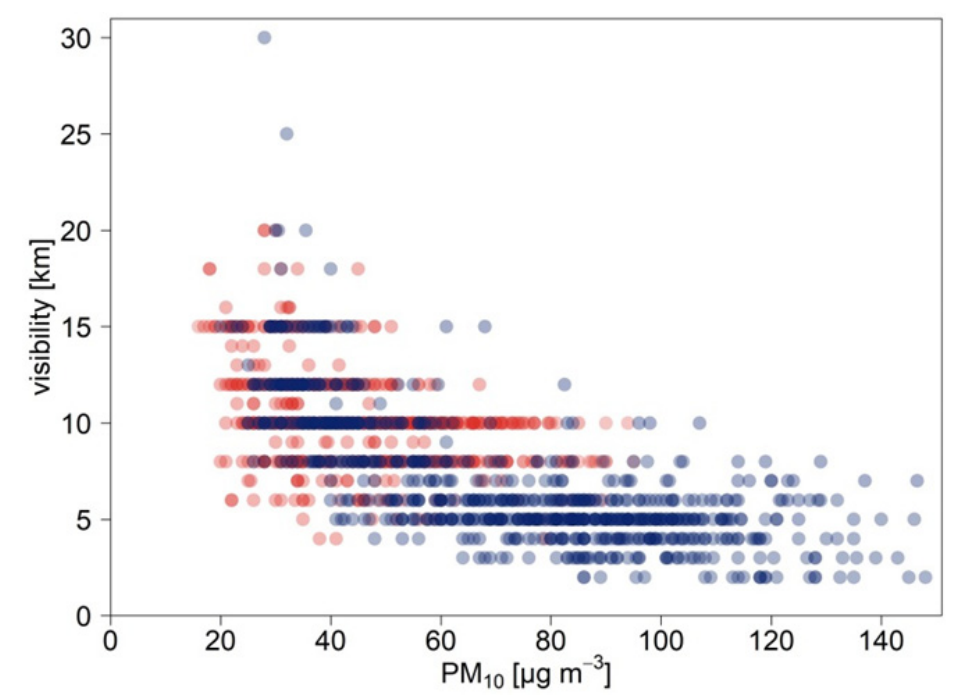

Fig. 5. Relationship between visibility (Vis) and mass concentration of $\mathrm{PM}_{10}$. The scatter points originate from monthly median data of the northern stations KL, TP, and TC (red points) and the southern stations CY, TN, and KS (blue points). 


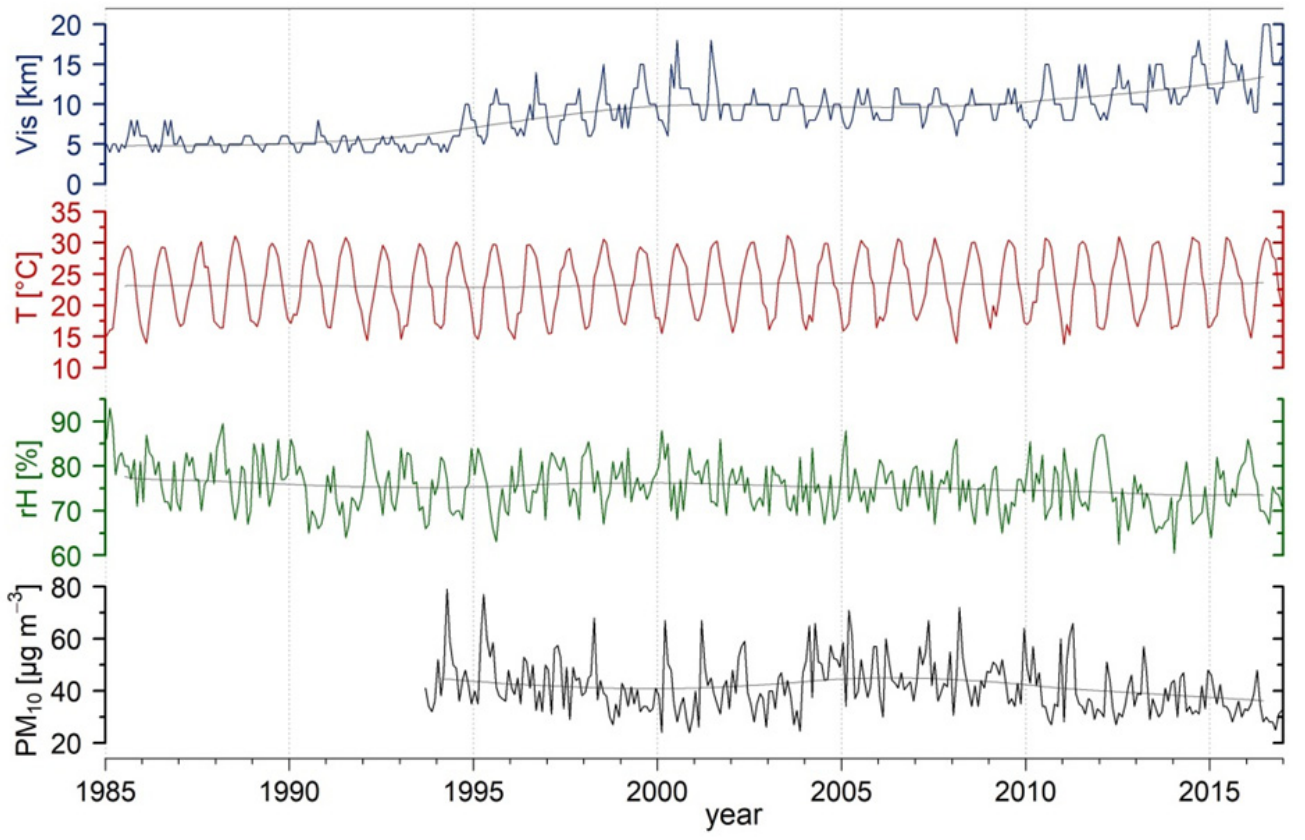

Fig. 6. Monthly median of Vis, $\mathrm{T}, \mathrm{rH}$, and $\mathrm{PM}_{10}$ in Taipei (TP). The grey line displays each parameter's underlying trend calculated with SSA. For the graphs of KL, TC, CY, and KS, see Supplement.

\section{CONCLUSIONS}

This study confirms that there have been long-term improvements in visibility conditions (e.g., an increase in the mean visibility and a reduction in the number of hazy and/or foggy days) for the urban inland sites of Taipei (TP), Taichung (TC), and Chiayi (CY). By contrast, the rural to suburban sites of Hengchun (HC) and Magong (MG) have exhibited a continuous decrease in the mean visibility. For urbanized coastal, and mountain sites, either no trend (Keelung (KL) and Yangming (YM)) or an overall decrease in visibility (Kaohsiung (KS), Tainan (TN), and Puli (PL)) was observed. However, a consistent increase in visibility within the most recent 5 to 10 years has been found for most of the stations, except for the rural regions of $M G$ and $\mathrm{HC}$. We confirmed a general significant decrease in the number of foggy days, which is mentioned in related literature, only for the urban stations of TC, CY, and KS.

Both the mean air pollution level and the regional climate are factors that determine the ambient visibility and how it responds to these and other drivers. Therefore, the results of the trend analysis, the correlation analysis and the relative importance analysis at the six urban stations offer a rather complex picture along a north-south gradient.

The observed visibility (Vis) displays stronger seasonality at the southwestern urban stations of $\mathrm{CY}, \mathrm{TN}$, and KS due to large seasonal variations in air quality (i.e., the levels of $\mathrm{PM}_{10}, \mathrm{NO}_{\mathrm{x}}$, and $\mathrm{SO}_{2}$ ) within a highly polluted area. The high relative importance and correlations indicate that the strongly fluctuating $\mathrm{PM}_{10}$ is the main contributor to the daily Vis variations at these southern stations, which are less strongly influenced by the precipitation and the relative humidity $(\mathrm{rH})$. At the northern urban stations of KL, TP, and $\mathrm{TC}$, the average particulate pollution level is lower and shows less seasonality. There, the daily Vis variations respond strongly to fluctuations in the $\mathrm{rH}$, which are generally more pronounced in the subtropical northern part of the island, and to those in the $\mathrm{PM}_{10}$. Vis thus exhibits smaller regular seasonal fluctuations.

Long-term changes in the $\mathrm{PM}_{10}$ have a weaker impact on changes in visibility at sites with higher mean $\mathrm{PM}_{10}$ levels than those with lower ones. As a consequence, Vis trends in highly polluted cities, such as $\mathrm{KS}, \mathrm{TN}$, and $\mathrm{CY}$, are mainly determined by changes in the relative humidity. Only in the last few years, when the pollution in these cities has begun to decline, has the influence of $\mathrm{PM}_{10}$ trends on Vis become evident. In the less polluted cities of TP and $\mathrm{TC}$, the changes in particulate matter more strongly impact the Vis trends, which are apparently also less affected by the decreasing $\mathrm{rH}$ trend.

In summary, this study reveals that the rise in temperature and the associated overall decline in relative humidity, which are due to a combination of climate change and urbanization, have had a positive influence on visibility conditions in the cities of Taiwan. The improved air quality has been a large contributor to the increasing visibility trends seen over the last 5 to 10 years, whereas it previously produced more results in the less polluted northern cities of TN and TC than in the southern cities. Currently, it is not clear whether the reduction in visibility at the rural to suburban lowland sites is due to an increase in air pollution or to an increase in relative humidity caused by intensified evapotranspiration as a result of climate change. Similarly, the origin of changes in visibility conditions at the mountain stations has not been identified. While changes in air quality certainly contribute to the general visibility conditions, changes in the frequency of fog occurrence at these sites are likely to be related to an elevated cloud base or lowered 
altitude for cloud condensation levels (caused by climate change), which can influence the general tendencies of cloud advection or fog formation at a specific station.

Note that the long-term variations in Vis at the six urban stations cannot be fully explained by the trends in $\mathrm{rH}$ or $\mathrm{PM}_{10}$. Moreover, only $54 \%$ to $61 \%$ of the variance in the daily Vis can be explained through the relative importance analysis. Further steps towards explaining the variations in the visibility, and understanding the frequency of lowvisibility events (i.e., occurrence of haze and fog), may include applying non-linear models. Regardless of the model, however, other processes that influence the visibility must also be considered. For example, changes in the composition of the ambient aerosol particles certainly strongly influence visibility because the hygroscopicity of particles determines their tendency to deliquesce and eventually act as CCN. However, data about aerosol particle chemistry were unavailable and thus not used in this study.

Another important factor is that the methodology for determining visibility was radically updated in 2015. As visual observations are replaced by automatic, instrumental visibility measurements, both the precision and the temporal coverage of visibility data will improve immensely. Therefore, future studies will likely be based on larger and more sophisticated datasets, which will allow for better analyses once more years of data have been collected.

Additionally, we propose a more detailed analysis of the seasons' visibility trends. Performing a seasonal trend analysis for the whole island of Taiwan was difficult because the characteristics and durations of the seasons differ considerably from southern to northern Taiwan, and, more importantly, vary from year to year. Therefore, such seasonal analyses should be conducted for geographically grouped study sites.

\section{ACKNOWLEDGMENTS}

We are grateful to the Taiwan Environmental Protection Administration (TEPA) for providing the air quality data obtained from the Taiwan Air Quality Monitoring Network (TAQMN), which is publicly available (https://taqm.epa.gov. tw/taqm/en/YearlyDataDownload.aspx). We also thank the Taiwan Central Weather Bureau (CBW) for providing the meteorological data used in this study and for guidance through several weather stations around Taiwan. We especially thank Weiti Tseng and Chia-Ching Lin, who helped during data acquisition and compilation. Travel funds from the German Academic Exchange Service (DAAD) through funds of the German Federal Ministry of Education and Research (BMBF) are acknowledged. We thank Celeste Brennecka for language editing of the manuscript. Last but not least, we thank two anonymous reviewers for helpful comments on an earlier version of this contribution.

\section{SUPPLEMENTARY MATERIAL}

Supplementary data associated with this article can be found in the online version at http://www.aaqr.org.

\section{REFERENCES}

Akimoto, Y. and Kusaka, H. (2015). A climatological study of fog in Japan based on event data. Atmos. Res. 151: 200-211.

Aldababseh, A. and Temimi, M. (2017). Analysis of the long-term variability of poor visibility events in the UAE and the link with climate dynamics. Atmosphere 8: 242.

Avotniece, Z., Klavins, M. and Lizuma, L. (2015). Fog climatology in Latvia. Theor. Appl. Climatol. 122: 97109.

Bokwa, A., Wypych, A. and Hajto, M.J. (2018). Impact of natural and anthropogenic factors on fog frequency and variability in Kraków, Poland in the years 1966-2015. Aerosol Air Qual. Res. 18: 165-177.

Bruijnzeel, L.A., Eugster, W. and Burkard, R. (2005). Fog as a hydrological input. In Encyclopedia of hydrological sciences, Anderson, M.G. (Ed.), John Wiley, Chichester, West Sussex, England, Hoboken, NJ, pp. 559-582.

Cao, J., Wang, Q., Chow, J.C., Watson, J.G., Tie, X., Shen, Z., Wang, P. and An, Z. (2012). Impacts of aerosol compositions on visibility impairment in Xi'an, China. Atmos. Environ. 59: 559-566.

Chan, K.L. and Chan, K.L. (2017). Aerosol optical depths and their contributing sources in Taiwan. Atmos. Environ. 148: 364-375.

Charlson, R.J., Schwartz, S.E., Hales, J.M., Cess, R.D., Coakley, J.A., Hansen, J.E. and Hofmann, D.J. (1992). Climate forcing by anthropogenic aerosols. Science 255 : 423-430.

Chen, S.P., Chang, C.C., Liu, J.J., Chou, C.C.K., Chang, J.S. and Wang, J.L. (2014). Recent improvement in air quality as evidenced by the island-wide monitoring network in Taiwan. Atmos. Environ. 96: 70-77.

Cheng, Y.F., Wiedensohler, A., Eichler, H., Heintzenberg, J., Tesche, M., Ansmann, A., Wendisch, M., Su, H., Althausen, D., Herrmann, H., Gnauk, T., Brüggemann, E., Hu, M. and Zhang, Y.H. (2008). Relative humidity dependence of aerosol optical properties and direct radiative forcing in the surface boundary layer at Xinken in Pearl River Delta of China: An observation based numerical study. Atmos. Environ. 42: 6373-6397.

Chung, Y.S., Kim, H.S. and Yoon, M.B. (1999). Observations of visibility and chemical compositions related to fog, mist and haze in South Korea. Water Air Soil Pollut. 111: 139-157.

Deng, J., Xing, Z., Zhuang, B. and Du, K. (2014). Comparative study on long-term visibility trend and its affecting factors on both sides of the Taiwan Strait. Atmos. Res. 143: 266-278.

Ding, P.H., Wang, G.S., Chen, B.Y. and Wan, G.H. (2016). Urban air pollution in Taiwan before and after the installation of a mass rapid transit system. J. Environ. Qual. 45: 1731.

European Parliament and Council of the European Union (2008). Directive 2008/50/EC of the European Parliament 
and of the Council of 21 May 2008 on ambient air quality and cleaner air for Europe. Official Journal of the European Union.

Executive Yuan, Republic of China (Taiwan) (2014). The Republic of China yearbook, Government Information Office, Taipei, Taiwan, ROC.

Forthun, G.M., Johnson, M.B., Schmitz, W.G. and Blume, J. (2006). Trends in fog frequency and duration in the southeast United States. Prog. Phys. 27: 206-222.

Golyandina, N. and Osipov, E. (2007). The "Caterpillar"SSA method for analysis of time series with missing values. J. Stat. Plan. Inference 137: 2642-2653.

Golyandina, N. and Korobeynikov, A. (2014). Basic singular spectrum analysis and forecasting with $\mathrm{R}$. Comput. Stat. Data Anal. 71: 934-954.

Golyandina, N., Korobeynikov, A., Shlemov, A. and Usevich, K. (2015). Multivariate and 2D extensions of singular spectrum analysis with the Rssa package. $J$. Stat. Software 67: 1-78.

Gonçalves, F.L.T., Rocha, R.P., Fernandes, G.P. and Petto, S. Jr. (2008). Drizzle and fog analysis in the São Paulo Metropolitan Area: Change 1933-2005 and correlations with other climate factors. Die Erde 139: 61-76.

Grömping, U. (2006). Relative importance for linear regression in R: The package relaimpo. J. Stat. Software 17: $1-27$.

Hand, J.L. (2011). Spatial and seasonal patterns and temporal variability of haze and its constituents in the United States (IMPROVE Report No. V), IMPROVE (Interagency Monitoring of Protected Visual Environments).

Hipel, K.W. and McLeod, A.I. (1994). Time series modelling of water resources and environmental systems, Developments in water science, Elsevier, Amsterdam, New York, USA.

Hirsch, R.M., Slack, J.R. and Smith, R.A. (1982). Techniques of trend analysis for monthly water quality data. Water Resour. Res. 18: 107-121.

Hu, Y., Yao, L., Cheng, Z. and Wang, Y. (2017). Longterm atmospheric visibility trends in megacities of China, India and the United States. Environ. Res. 159: 466473.

Jin, Y., Andersson, H. and Zhang, S. (2016). Air pollution control policies in China: A retrospective and prospects. Int. J. Environ. Res. Public Health 13: 1219.

Junker, C., Wang, J.L. and Lee, C.T. (2009). Evaluation of the effect of long-range transport of air pollutants on coastal atmospheric monitoring sites in and around Taiwan. Atmos. Environ. 43: 3374-3384.

Kendall, M.G. and Gibbons, J.D. (1990). Rank correlation methods, 5 ed. Arnold, London, UK.

Klemm, O. and Lin, N. (2016). What causes observed fog trends: Air quality or climate change? Aerosol Air Qual. Res. 16: 1131-1142.

Korobeynikov, A. (2010). Computation- and space-efficient implementation of SSA. Stat. Interface 3: 357-368.

Kuo, C.Y., Cheng, F.C., Chang, S.Y., Lin, C.Y., Chou, C.C.K., Chou, C.H. and Lin, Y.R. (2013). Analysis of the major factors affecting the visibility degradation in two stations. J. Air Waste Manage. Assoc. 63: 433-441.

LaDochy, S. and Witiw, M. (2012). The continued reduction in dense fog in the Southern California region: Possible causes. Pure Appl. Geophys. 169: 1157-1163.

Li, T.C., Yuan, C.S., Lo, K.C., Hung, C.H., Wu, S.P. and Tong, C. (2015). Seasonal variation and chemical characteristics of atmospheric particles at three islands in the Taiwan Strait. Aerosol Air Qual. Res. 15: 22772290.

Lin, C.Y., Liu, S.C., Chou, C.C., Liu, T.H., Lee, C.T., Yuan, C.S., Shiu, C.J. and Young, C.Y. (2004). Longrange transport of Asian dust and air pollutants to Taiwan. Terr. Atmos. Ocean. Sci. 15: 759-784.

Lin, J.C.H., Tai, J.H., Feng, C.H. and Lin, D.E. (2010). Towards improving visibility forecasts in Taiwan: A statistical approach. Terr. Atmos. Ocean. Sci. 21: 359.

Lin, M., Tao, J., Chan, C.Y., Cao, J.J., Zhang, Z.S. and Zhu, L.H. (2012). Regression analyses between recent air quality and visibility changes in megacities at four haze regions in China. Aerosol Air Qual. Res. 12: 10491061.

Lin, N.H., Tsay, S.C., Maring, H.B., Yen, M.C., Sheu, G.R., Wang, S.H., Chi, K.H., Chuang, M.T., Ou-Yang, C.F., Fu, J.S., Reid, J.S., Lee, C.T., Wang, L.C., Wang, J.L., Hsu, C.N., Sayer, A.M., Holben, B.N., Chu, Y.C., Nguyen, X.A., Sopajaree, K., Chen, S.J., Cheng, M.T., Tsuang, B.J., Tsai, C.J., Peng, C.M., Schnell, R.C., Conway, T., Chang, C.T., Lin, K.S., Tsai, Y.I., Lee, W.J., Chang, S.C., Liu, J.J., Chiang, W.L., Huang, S.J., Lin, T.H. and Liu, G.R. (2013). An overview of regional experiments on biomass burning aerosols and related pollutants in Southeast Asia: From BASE-ASIA and the Dongsha Experiment to 7-SEAS. Atmos. Environ. 78: $1-19$.

Lindeman, R.H., Merenda, P.F. and Gold, R.Z. (1980). Introduction to bivariate and multivariate analysis, Scott, Foresman, Glenview, Ill.

Mann, H.B. (1945). Nonparametric tests against trend. Econometrica 13: 245.

Pohlert, T. (2016). Non-parametric trend tests and changepoint detection. CC BY-ND 4.

Pohlert, T. (2018). trend: Non-parametric trend tests and change-point detection. R Package version.

$\mathrm{R}$ Core Team (2017). $R$ : A language and environment for statistical computing, $\mathrm{R}$ Foundation for Statistical Computing, Vienna, Austria.

Sabbagh-Kupelwieser, N., Horvath, H. and Szymanski, W.W. (2010). Urban aerosol studies of $\mathrm{PM}_{1}$ size fraction with reference to ambient conditions and visibility. Aerosol Air Qual. Res. 10: 425-432.

Sabetghadam, S. and Ahmadi-Givi, F. (2014). Relationship of extinction coefficient, air pollution, and meteorological parameters in an urban area during 2007 to 2009. Environ. Sci. Pollut. Res. Int. 21: 538-547.

Seinfeld, J.H. and Pandis, S.N. (2016). Atmospheric chemistry and physics: From air pollution to climate change. John Wiley \& Sons, New Jersey, USA.

Sulkava, M., Luyssaert, S., Rautio, P., Janssens, I.A. and Hollmén, J. (2007). Modeling the effects of varying data 
quality on trend detection in environmental monitoring. Ecol. Inf. 2: 167-176.

Tang, D.T.C. (1993). The environmental laws and policies of Taiwan: A comparative law perspective. Pa. Rim Law Policy Assoc. 3: 89.

Tsai, J.H., Huang, K.L., Lin, N.H., Chen, S.J., Lin, T.C., Chen, S.C., Lin, C.C., Hsu, S.C. and Lin, W.Y. (2012). Influence of an Asian dust storm and Southeast Asian biomass burning on the characteristics of seashore atmospheric aerosols in southern Taiwan. Aerosol Air Qual. Res. 12: 1105-1115.

Tsai, Y.I., Lin, Y.H. and Lee, S.Z. (2003). Visibility variation with air qualities in the metropolitan area in southern Taiwan. Water Air Soil Pollut. 144: 19-40.

Tsai, Y.I. and Cheng, M.T. (2004). Characterization of chemical species in atmospheric aerosols in a metropolitan basin. Chemosphere 54: 1171-1181.

Tsai, Y.I. (2005). Atmospheric visibility trends in an urban area in Taiwan 1961-2003. Atmos. Environ. 39: 55555567.

Tsai, Y.I., Kuo, S.C., Lee, W.J., Chen, C.L. and Chen, P.T. (2007). Long-term visibility trends in one highly urbanized, one highly industrialized, and two Rural areas of Taiwan. Sci. Total Environ. 382: 324-341.

Tsai, Y.I., Sopajaree, K., Kuo, S.C. and Hsin, T.Y. (2015). Chemical composition and size-fractionated origins of aerosols over a remote coastal site in southern Taiwan. Aerosol Air Qual. Res. 15: 2549-2570.

Twomey, S. (1991). Aerosols, clouds and radiation. Atmos. Environ. 25: 2435-2442.

Vautard, R., Yiou, P. and van Oldenborgh, G.J. (2009). Decline of fog, mist and haze in Europe over the past 30 years. Nat. Geosci. 2: 115-119.

World Meteorological Organization (1994). Commission for instruments and methods of observation: Abridged final report of the eleventh session, Geneva, 21 February 4 March 1994, WMO-No. 807, Secretariat of the World Meteorological Organization, Geneva, Switzerland.

World Meteorological Organization (2014). Aerodrome reports and forecasts: A users' handbook to the codes, WMO-No. 752, 5th ed, World Meteorological Organization, Geneva, Switzerland.

World Meteorological Organization (2017). Guide to meteorological instruments and methods of observation, WMO-No. 8, World Meteorological Organization, Geneva, Switzerland.

Ye, H. (2009). The influence of air temperature and atmospheric circulation on winter fog frequency over Northern Eurasia. Int. J. Climatol. 29: 729-734.

Yuan, C.S., Lee, C.G., Liu, S.H., Chang, J., Yuan, C. and Yang, H.Y. (2006). Correlation of atmospheric visibility with chemical composition of Kaohsiung aerosols. Atmos. Res. 82: 663-679.

Zhang, Q., Quan, J., Tie, X., Li, X., Liu, Q., Gao, Y. and Zhao, D. (2015). Effects of meteorology and secondary particle formation on visibility during heavy haze events in Beijing, China. Sci. Total Environ. 502: 578-584.

Zhang, Y., Huang, W., Cai, T., Fang, D., Wang, Y., Song, J., Hu, M. and Zhang, Y. (2016). Concentrations and chemical compositions of fine particles $\left(\mathrm{PM}_{2.5}\right)$ during haze and non-haze days in Beijing. Atmos. Res. 174175: 62-69.

Zuur, A.F., Ieno, E.N. and Elphick, C.S. (2010). A protocol for data exploration to avoid common statistical problems: Data exploration. Methods Ecol. Evol. 1: 3-14.

Received for review, April 30, 2018 Revised, October 1, 2018 Accepted, November 12, 2018 